\title{
Leadership styles: The role of cultural intelligence
}

Authors:
Anthony Solomon ${ }^{1}$
Renier Steyn ${ }^{1}$
Affiliations:
${ }^{1}$ Graduate School of Business
Leadership, University of
South Africa, South Africa
Corresponding author:
Anthony Solomon,
78799139@mylife.unisa.
ac.za
Dates:
Received: 13 Feb. 2017
Accepted: 24 May 2017
Published: 24 July 2017
mobile phone or
How to cite this article:
Solomon, A., \& Steyn, R.
(2017). Leadership styles: The
role of cultural intelligence.
SA Journal of
Industrial Psychology/SA
Tydskrif vir Bedryfsielkunde,
43(0), a1436. https://doi.
org/10.4102/sajip.v43i0.1436
Copyright:
C 2017. The Authors.
Licensee: AOSIS. This work
is licensed under the
Creative Commons
Attribution License.

Orientation: Within both the South African context and abroad, leaders are increasingly being required to engage with staff members whose cultures differ from their own. As the attractiveness of different leadership styles varies in line with staff member cultural preferences, the challenge leaders face is that their behaviours may no longer be apposite. To this end, it is mostly unknown whether those leaders who are deemed culturally intelligent behave in a specific manner, that is, display the empowering and directive leadership styles.

Research purpose: The purpose of this study was to explore the relationship between leader cultural intelligence and the empowering and directive styles of leadership, as perceived by subordinates.

Motivation for the study: To operate successfully, leaders need to adopt and display those leadership styles that best match the cultural expectations of their staff members. Cultural intelligence may assist in this respect. Most of the studies on leader cultural intelligence and leadership styles have concentrated on the transformational leadership style. There is, thus, a requirement to examine how leader cultural intelligence relates to other leadership styles.

Research design, approach and method: The study was quantitative in nature and made use of a cross-sectional survey design. Data were collected from 1140 staff members spread across 19 diverse organisations carrying on business activities in South Africa. Correlation and regression techniques were performed to identify relationships.

Main findings: Leader cultural intelligence was found to have a stronger relationship with empowering leadership than it had with directive leadership. With empowering leadership, leader metacognitive and motivational cultural intelligence acted as important antecedents, whilst for directive leadership, leader's motivational, cognitive and metacognitive cultural intelligence played a predictive part that carried a medium effect.

Practical/managerial implications: The findings can be used by organisations to guide the selection of leaders and to focus initiatives for their development.

Contribution and value-add: The study adds to the cultural intelligence and leadership literature by offering empirical evidence of the relationship between leader cultural intelligence and the empowering and directive leadership styles.

\section{Introduction}

Despite the issue of leadership having held humankind's attention for thousands of years (Blunt \& Jones, 1997; Fry, Vitucci \& Cedillo, 2005; Hassan, Asad \& Hoshino, 2016; Higgs, 2003; Vie \& Vie, 2011), a measure of uncertainty still exists as to what it really is (Bolden, 2004; Iszatt-White, Graham, Kelly, Randall \& Rouncefield, 2011). This is especially perturbing because leadership is accepted as central to the success of organisations (Hanges, Aiken, Park \& Su, 2016; Landis, Hill \& Harvey, 2014). The lack of certainty is compounded by phenomena such as globalisation that are increasingly exposing leaders to new challenges (Ababneh, 2016; Jogulu, 2010), not the least of which is leading in a multicultural environment (Parham, Lewis, Fretwell, Irwin \& Schrimsher, 2015). This is key as the composition of the workforce is becoming ever more culturally diverse (Groves \& Feyerherm, 2011; Strydom \& Eeden, 2013) and because an interdependent relationship exists between leadership and (personal) culture (Paulienė, 2012; Snaebjornsson \& Edvardsson, 2013; Steers, Sanchez-Runde \& Nardon, 2012). To this end, Dickson, Castaño, Magomaeva and Den Hartog (2012) declare that (personal) cultures are of utmost importance in the leadership context. It is thus suggested that leadership styles should be modified so that they are congruent with these cultures (Alon \& Higgins, 2005) as successful leadership styles vary across them (Ng, Van Dyne \& Ang, 2009). Furthermore, (personal) culture is important as it affects how leaders are chosen, viewed and developed (Dickson et al., 2012). The obstacle facing leaders, however, is that they are often oblivious to their own cultural prism through which they perceive others (Offermann \& Phan, 2008). 
Caldwell (2015) argues that a tsunami of cultures is rapidly increasing the requirement for and criticality of having competent and capable leaders with those attributes that allow them to lead globally. Northouse (2013) submits that leaders must develop proficiencies in both cross-cultural cognisance and application, whereas Javidan and Dastmalchian (2009) remark that leaders should be able to contrast their own cultures with those of others, the ability to efficaciously traverse the chasm that prevails between the aforesaid cultures requires a capability that extends beyond merely understanding them. Ang, Van Dyne and Rockstuhl (2015) point out that cultural intelligence (CQ), the capability to 'grasp, reason and behave effectively in situations characterized by cultural diversity' (Ang et al., 2007, p. 337), assists in overcoming cultural dissimilarities. Advancing a leader's CQ is therefore vital, specifically so because Robinson (2016) states that it is of paramount importance that leaders hone a multifaceted skills repertoire to deal with an everexpanding array of complex problems. Since CQ is regarded as a malleable capability it can be developed and enhanced (Ng et al., 2009; Ramsey \& Lorenz, 2016).

As culture influences leadership styles (Bass \& Bass, 2008; House, Javidan \& Dorfman, 2001; Jogulu, 2010), it is reasonable to expect that culturally intelligent leaders will display the style(s) of leadership most compatible with the cultures of their subordinates. Klenke (2009) asserts that central to CQ is a leader's ability to adapt. With this in mind, Livermore (2010) reports that adapting their leadership style is one of the key reasons leaders cite as to why CQ is required if they are to be successful in leading culturally diverse followers. Similarly, Du Plessis (2011), in her study of 353 South African managers, found that adaptive capability emerged as an important competency arising from managerial CQ.

The importance of culture within the leadership context and the role that CQ could occupy in assisting leaders to display appropriate (i.e. culturally attractive) leadership styles has been highlighted in the above discussion. However, even though the volume of literature on CQ has been increasing steadily since its initial conceptualisation by Earley and Ang (2003), empirical examination of leader CQ remains scarce (Groves \& Feyerherm, 2011; Vanderpal, 2014), especially so in the case of its relationship with leadership styles. Furthermore, the few studies that have investigated this relationship have mostly concentrated on the transformational leadership style (Elenkov \& Manev, 2009; Ismail, Reza \& Mahdi, 2012; Keung \& Rockinson-Szapkiw, 2013; Lee, Veasna \& Wu, 2013). As Ensley, Hmieleski and Pearce (2006) maintain that both empowering and directive leadership must be considered if leaders with a complete range of behavioural capabilities are to be developed, it is evident that further research is necessary to better comprehend the relationship between leader CQ and empowering and directive leadership. This understanding should assist both line and human resource personnel in identifying those candidates best suited to lead in cross-cultural conditions. Similarly, the concomitant composition of CQ training programmes aimed at the growth of leaders could be enhanced.

\section{Research purpose and objective}

The purpose of this study was to investigate the relationship between leader $C Q$ and the empowering and directive leadership styles. As such, the objective was to determine whether leadership style (as represented by empowering and directive leadership) is a function of leader CQ.

\section{Literature review}

The literature review sought to: (1) provide an overview of $C Q$, empowering and directive leadership and (2) consider existing insights on the relationship between leader CQ and leadership styles.

\section{Cultural intelligence}

Initial research efforts into intelligence, given the application of a tapered perspective, tended to associate intelligence solely with academic settings (Ang, Van Dyne \& Tan, 2011). A growing interest in intelligence, however, has resulted in its classification per a range of foci such as emotional, social and general mental ability (Zhang, 2012). These intelligences account for most of the variations between the achievement levels of persons in the personal, social and work domains within their own cultures (Viggiano, 2016).

To fully explain intelligence, however, Sternberg and Grigorenko (2006) submit that cultural context must be considered. It is against this background that the concept of CQ was originally conceptualised and has evolved accordingly. CQ is founded upon the Sternberg and Detterman (1986) multiple loci of intelligence framework (Ang et al., 2011; Eisenberg et al., 2013; Kurpis, 2012; Ng et al., 2009; Peng, Van Dyne \& Oh, 2015; Zhang, 2012). Although related to cognitive intellect as well as emotional and social intelligence (Ang et al., 2015), CQ situates discretely (Ang et al., 2007) largely due to the aforementioned intelligences being culture specific (Thomas et al., 2008). Contrasting them, CQ depicts an etic perception of intelligence as it transfers across cultures (Klenke, 2009; Ng \& Earley, 2006).

Culturally intelligent persons are competent and effectual in multiple intercultural interactions as opposed to just a single or a few such exchanges (Ang \& Inkpen, 2008; Ang et al., 2015). Thomas (2006) notes that CQ depicts the capability to not simply adjust to but actually influence the cross-cultural exchange. Accordingly, CQ helps to explain why some leaders easily adjust their perspectives and behaviours across cultures whilst others do not (Van Dyne, Ang \& Livermore, 2010). Although various scholars, such as Fung and Lo (2017) as well as Thomas and Inkson (2005), have offered their own conceptualisation of CQ, that which was advanced by Earley and Ang (2003) has proven most popular in underpinning CQ research (Ott \& Michailova, 2016). In terms of this last-mentioned model, CQ is theorised as possessing cognitive, motivational and behavioural components. A fourth component, metacognition, was subsequently added by Ang and Van Dyne (2008). The study on which this article reports made use of the Earley and Ang (2003) and Ang and Van Dyne (2008) CQ conceptualisation. 
The four components or dimensions of $\mathrm{CQ}$ reflect different competencies ( $\mathrm{Ng}$, Van Dyne \& Ang, 2012). Metacognition refers to higher-order cognitive procedures (Charoensukmongkol, 2016), that is, the processes through which persons source and grasp knowledge (Ang \& Inkpen, 2008) and, hence, reflects the ability of a leader to strategise when traversing cultures (Van Dyne et al., 2010). As such, metacognitive CQ stimulates the formation of novel heuristics for intercultural interfaces and promotes the questioning of one's own cultural suppositions (Ang et al., 2011). Cognition, the second of the CQ dimensions, represents a person's knowledge about other cultures, examples of which include customs, standards and values (Van Dyne et al., 2012). This dimension of $C Q$, thus, signifies the extent to which a leader comprehends how to engage with others cross-culturally (Van Dyne et al., 2010). Ang et al. (2011), though, warn that unless the know-how emanating from cognitive CQ is assimilated into the other CQ dimensions, it is possible that such knowledge may not be of much value to leaders and could indeed be harmful. A leader, for example, with relevant cultural insights who lacks the desire (motivation) to display pertinent actions (behaviours) based on these might be viewed adversely by subordinates. The third dimension, motivational CQ, portrays the leader's desire to acclimate interculturally (Van Dyne et al., 2010), that is, the energy expended in both acquiring knowledge about other cultures and immersing oneself in cross-cultural interfaces ( $\mathrm{Ng}$ et al., 2012). Finally, behavioural CQ denotes the adoption and display of culture-appropriate actions (Ang \& Van Dyne, 2008) that may be both verbal and non-verbal (Van Dyne, Ang \& Nielsen, 2008). Ang et al. (2007) indicate that the dimensions 'may or may not correlate with each other' ( $\mathrm{p}$. 338), whilst Magnusson, Westjohn, Semenov, Randrianasolo and Zdravkovic (2013) argue that the dimensions are comparatively independent. In combination, the dimensions reflect the understanding that CQ concerns the integration of knowledge about cultural disparities with the impetus and competence to consider one's own and other persons' cultural programming, combined with the ability to display culturally apt behaviours (Schreier \& Kainzbauer, 2016).

\section{Empowering and directive leadership}

Although an abundance of leadership theories and styles exists (Avolio, Walumbwa \& Weber, 2009; Brauckmann \& Pashiardis, 2011; Esen, 2015; Landis et al., 2014; Perkins, 2013), leadership is most often demarcated according to leader traits, qualities and behaviours (Horner, 1997). Concentrating on leader behaviours, Pearce et al. (2003) defined a typology consisting of the transactional, transformational, empowering and directive leadership styles. Transactional leadership is considered by Golla and Johnson (2013) to be a style in which leaders promote employee self-interest through the promise of rewards in return for performance. Transformational leadership targets the attainment of organisational objectives by offering staff members a vision that eclipses their self-interest (Holten, Bøllingtoft \& Wilms, 2015). Although the transactional and transformational leadership paradigm has attracted much scholarly attention (Clark \& Waldron, 2016; Sims, Faraj \& Yun, 2009), Hmieleski and Ensley (2007) insist that such leadership styles are often reflective of ambiguous behaviours. In contrast, empowering and directive leadership, on which empirical insights remain scanty (Kalaluhi, 2013; Sharma \& Kirkman, 2015; Tekleab, Sims, Yun, Tesluk \& Cox, 2008), are distinct from one another (Yun, Cox \& Sims, 2006) and are situated at opposing ends of an action-based spectrum (Faraj \& Sambamurthy, 2006). This research focussed on these last-mentioned leadership styles primarily because empirical investigation of them is limited. Further, as noted above, the transformational leadership style has dominated attention in the domain of leader CQ and there is some uncertainty as to the distinction between transformational and transactional leadership behaviours in the literature.

In the light of heightened global economic rivalry and with a view to improving their agility, many organisations have adapted their structural composition to reflect a more empowered workforce as opposed to the hierarchical leadership arrangements of yesteryear (Arnold, Arad, Rhoades \& Drasgow, 2000). Empowering leadership aims to grow the capacity of followers to lead themselves (Mohamed, 2016; Tekleab et al., 2008) and may be defined as behaviours that promote power equality with staff members (Amundsen \& Martinsen, 2014) or as the assignment of authority and responsibilities to subordinates (Hakimi, van Knippenberg \& Giessner, 2010).

Empowering leadership embraces divergent employee viewpoints (Doh \& Quigley, 2014) whilst spotlighting employee self-control advancement (Galanou, 2009). Ahearne, Mathieu and Rapp (2005) note that leader empowering behaviours consist of (1) enhancing work meaningfulness, that is, the extent to which a leader sets stimulating goals for subordinates and clarifies their contributions to organisational success (Kwak \& Jackson, 2015), (2) encouraging decision-making involvement or the extent to which the leader facilitates decision-making by subordinates (Kwak \& Jackson, 2015), (3) voicing sureness of high performance by, for example, attesting to subordinates' capabilities (Kwak \& Jackson, 2015) and (4) removing bureaucratic constraints or the degree to which a leader dissipates organisational factors that inhibit subordinates' independence (Kwak \& Jackson, 2015).

The empowering leadership style influences psychological empowerment positively (Amundsen \& Martinsen, 2015; Joo, Park \& Lim, 2016; Raub \& Robert, 2012). It prompts followers' perceptions of increased work challenges (Esteves \& Lopes, 2017) and stimulates their feelings of self-efficacy (Biemann, Kearney \& Marggraf, 2015; Bobbio, Bellan \& Manganelli, 2012; Kim \& Beehr, 2017). It demonstrates a positive relationship with employee creativity (Harris, Li, Boswell, Zhang \& Xie, 2014; Zhang \& Zhou, 2014) and innovative behaviour (Gkorezis, 2016). Empowering leadership also correlates with employees' organisational job embeddedness (Erkutlu \& Chafra, 2015) as well as with their 
work effort, performance and service delivery levels (Govender, 2016). It increases the extent of knowledge sharing between team members (Lee, Lee \& Park, 2014) and change-orientated organisational citizenship behaviours ( $\mathrm{Li}$, Liu, Han \& Zhang, 2016). The strengthening of relationships with managers and colleagues (Esteves \& Lopes, 2017) as well as the advent of informal leadership (Adeel \& Pengcheng, 2016) are also associated with this style of leadership.

Directive leadership, on the other hand, is based upon positional power (Lorinkova, Pearsall \& Sims, 2013; Yun et al., 2006) and depicts behaviours that provide subordinates with precise direction concerning objectives, how such objectives must be realised and the outputs required (Martin, Liao \& Campbell, 2013). As such, it embodies behaviours that are mostly aligned with task accomplishment (Dewettinck \& van Ameijde, 2011). Accordingly, those leaders who adopt this style deliver leadership through the issuing of orders, commands and directives (Sims et al., 2009) based primarily upon their own judgements (Yun, Cox, Sims \& Salam, 2007).

Directive leadership has been associated with some negative outcomes such as reduced team cohesiveness (Wendt, Euwema \& van Emmerik, 2009) and slower product development (McDonough \& Barczak, 1991). It does, however, influence employee role clarity positively (Dolatabadi \& Safa, 2011). This style of leadership is also positively associated with a reduction in job demands that impede workers in the execution of their duties (Esteves \& Lopes, 2017). Furthermore, it has a positive relationship with organisational commitment (Somech, 2005) and correlates with the quality of group results (Sagie, 1997) and processes (Peterson, 1997). Directive leadership is also an appropriate leadership style when subordinates lack requisite skills (Muczyk \& Reimann, 1987), a major calamity is encountered (Maggitti, Slay \& Clark, 2010) or the work activities are structured and routine (Sauer, 2011).

\section{Cultural intelligence and leadership styles}

As pointed out in the introduction, transformational leadership appears to be the style that has attracted the most attention in the domain of CQ. Leader CQ, as an aggregate construct, cognitive CQ and behavioural CQ have all been confirmed as coinciding with transformational leadership (Ismail et al., 2012; Keung \& Rockinson-Szapkiw, 2013). In addition, Ismail et al. (2012) found that transformational leadership coincided with both leader metacognitive and motivational CQ. Leader CQ also acted as a moderator of the transformational leadership relationship with both expatriate adjustment and performance (Lee et al., 2013) as well as organisational innovation (Elenkov \& Manev, 2009). The relationship between the autocratic, democratic and laissez-faire leadership styles and the leader CQ dimensions was investigated by Eken, Özturgut and Craven (2014). Apart from reporting a positive relationship between leader motivational $\mathrm{CQ}$ and the democratic leadership style, these researchers were unable to detect any other significant associations. The authors are not aware of any empirical studies that have specifically concentrated on the relationship between leader CQ and both the empowering and directive leadership styles.

The following null hypotheses were thus set:

$\mathbf{H 1}_{0}$ : There is no statistically significant relationship between the CQ (as a composite value) and the empowering leadership style of leaders at organisations operating in South Africa.

$\mathbf{H 2}$ : There is no statistically significant relationship between the CQ (as a composite value) and the directive leadership style of leaders at organisations operating in South Africa.

H3: The relationship between leader CQ (as a composite value) and the empowering leadership style does not differ from that between leader CQ (as a composite value) and the directive leadership style.

$\mathrm{H4}_{0}$ : There is no statistically significant relationship between each of the CQ dimensions and the empowering leadership style of leaders at organisations operating in South Africa.

H5: There is no statistically significant relationship between each of the CQ dimensions and the directive leadership style of leaders at organisations operating in South Africa.

H6: All the leader CQ dimensions do not contribute uniquely and significantly in predicting the empowering leadership style of leaders at organisations operating in South Africa.

H7: All the leader CQ dimensions do not contribute uniquely and significantly in predicting the directive leadership style of leaders at organisations operating in South Africa.

\section{Research design Research approach}

This study, anchored within the positivist paradigm, followed a quantitative methodology. Specifically, a cross-sectional approach was adopted. Cross-sectional surveys are well suited for descriptive research and those studies aimed at exploring relationships between variables (Shaughnessy, Zechmeister \& Zechmeister, 2012).

\section{Research method}

\section{Research participants}

The population consisted of all leaders (i.e. anyone to whom another staff member directly reports) at all organisations operating in South Africa. Conway (2000) and Kim and Yukl (1995) draw attention to the benefits of employing subordinate ratings as opposed to leaders self-reporting, whilst Ang et al. (2015) highlight the advantages of using informant-based CQ measures. Hence, sample data on the leaders were sourced from their subordinates.

The sample respondents, being the subordinates of the leaders, were recruited by students pursuing a Master of Business Leadership (MBL) degree through the Graduate 
School of Business Leadership at the University of South Africa (GSBL). The students, by means of their respective employers, gained access to the respondents. The students then acted as fellow researchers collecting data from 18 different South African organisations.

The corresponding author also collected data from the organisation by whom he is employed. In aggregate, data were collected from 1140 respondents across the 19 organisations. Six of the organisations trade within the manufacturing industry whilst another three operate within the telecommunications industry. Three of the organisations represent the media industry and a further two fall within the public sector. The defence industry was represented by a single organisation as was the banking sector. The remaining organisations were from the services industry. Although the respondents were selected on a random basis, from the personnel records in the participating organisations, the sample was based upon convenience as the choice of organisations was not random.

\section{Measuring instruments}

The following instruments, with the permission of their respective authors, were used to measure the variables and were presented to the respondents in the form of a single consolidated questionnaire. Details of the instruments appear below and are arranged per variable.

Leader CQ: Measured by the Cultural Intelligence Scale (CQS) devised by Van Dyne, Ang and Koh (2008) who note that both the self and observer report versions of the CQS are convergent, discriminant and criterion valid. Rockstuhl, Seiler, Ang, Van Dyne and Annen (2011) further point out that the CQS is reliable, based on Cronbach's coefficient alphas (that ranged from 0.71 to 0.85 ) achieved by Van Dyne et al. (2008), and may be generalised across samples, time and cultures. This research made use of the observer report version.

Empowering leadership: Evaluated via the 10-item instrument of Ahearne et al. (2005). Yoon (2012) confirmed the reliability of this instrument (Cronbach's coefficient alpha of 0.93), whilst Zhang and Bartol (2010) remark that it depicts the distinctiveness of empowering leadership.

Directive leadership: Assessed through six items developed by Pearce and Sims (2002) and four from Hwang et al. (2015). Hinrichs (2011) states that the items developed by Pearce and Sims (2002) have delivered acceptable levels of reliability (Cronbach's coefficient alpha of 0.88), whilst Hwang et al. (2015) note a similar result in respect of the items they developed (Cronbach's coefficient alpha of 0.85 ).

\section{Research procedure}

Following receipt of permission from the GSBL Research Ethics Review Committee for the data to be collected, participating MBL students were fully briefed on the nature, purpose and importance of the research. The questionnaire as well as the respondent information sheet were explained to them. Each student first sourced the written approval of his or her employer's chief executive officer, or other appropriate executive, on the basis that it would not be named. Thereafter, a list of potential respondents (i.e. subordinates of the leaders) was obtained from the human resource department. Each name on the list was allocated a number. Potential respondents were then selected randomly using a random number generator. Chosen persons were invited to a meeting at which the research was introduced to them. They were advised that participation was completely voluntary and anonymous. Those staff members who agreed to participate were handed a hard copy of the questionnaire and were requested to complete it at the meeting, after which they returned it to the respective student. The reason why a hard copy, rather than a soft copy, of the questionnaire was used is because it facilitated completion during the aforementioned meeting rather than having to follow up with the respondents (potentially on numerous occasions) following the meeting. An Excel-based template was then provided by the authors to the students wherein each captured the details from the questionnaires they had collected. The populated templates were then consolidated. The corresponding author followed the same research procedure in collecting the data from his employer.

\section{Statistical analysis}

IBM SPSS (version 24) (Field, 2012) was used to perform the data analysis. Frequencies were calculated to provide a descriptive view of respondent demographics. Measures of central tendency were also computed for the different variables included. Cronbach's coefficient alphas were calculated to assess reliability. Reliability was accepted as satisfactory where the alpha scores exceeded 0.70 , with scores above 0.80 being taken as desirable (Pallent, 2011).

Validity was examined through principal axis factor analysis with direct Oblimin rotation. The number of factors retained was based upon the rule of thumb that only those factors with eigenvalues larger than one would be included (Coovert \& McNelis, 1988). Factor numbers were also confirmed through an examination of scree plots, as recommended by Costello and Osborne (2005). The process, as described by Courtney (2013), for such examination was followed; that is, the scree plot was scanned for a break or hinge (also referred to as an 'elbow'). The number of factors was considered to be the number of eigenvalues appearing before the elbow. Factor acceptability was evaluated with reference to the guidelines of Hair, Black, Babin and Anderson (2010) and Osborne and Costello (2009), which indicate that item loadings of 0.30-0.40 are minimally acceptable whilst loadings of 0.50 and greater are favoured. Although factors that have at least four adequately loading items are generally noted to be acceptable (Osborne \& Costello, 2009), there is little guidance in the literature as to the suitable number of items that should load when measurement scale length is considered. Hence, for a factor to be accepted in this research, it was decided that at least $80 \%$ of the respective items measuring it should load with a minimum weight of 0.50 each. 
Pearson product-moment correlation coefficients were calculated to gauge the relationships between the variables. Only statistically significant correlations were considered. Significance was taken at the $5 \%$ level as recommended by Lazaraton (1991). To assess the practical significance of the alphas, the guidelines of Cohen (1988) were followed; that is, correlation coefficients above 0.10 were accepted as small, those exceeding 0.30 were appraised as medium and those greater than 0.50 were taken as large. The online calculator of Lee and Preacher (2013), which is based upon the Fisher r-to-z transformation and the asymptotic equations of Steiger (1980), was used to evaluate the difference between correlations.

The ability of the leader CQ dimensions to predict empowering and directive leadership was determined through stepwise regression analysis. Only those dimensions that contributed statistically significant predictions were considered. The $f^{2}$ statistic was used in judging the practical significance of the models; in this regard, the conclusions of Ellis and Steyn (2003) based on the guidelines of Cohen (1988) were followed. According to Ellis and Steyn (2003), where $f^{2}<0.15$, the effect is small and $R^{2}$ is not practically significant, where $0.15<f^{2}<0.35$, the effect is medium and $R^{2}$ is practically significant and where $f^{2}>0.35$, the effect is large and thus $R^{2}$ is practically important. Emphasis was placed on those betas that contributed uniquely and independently to the variance in the dependent variable.

\section{Results}

The results of the data analysis are as follows.

\section{Respondent demographics}

Descriptive statistics were calculated for respondent gender, race and age and are shown in Tables 1,2 and 3, respectively.

The genders were approximately equally represented in the sample.

The sample race demographics were broadly in line with the Statistics South Africa (2016) Quarterly Labour Force Survey

\begin{tabular}{lccc}
\multicolumn{4}{l}{ TABLE 1: Respondent gender. } \\
\hline Gender & Frequency & $\mathbf{\%}$ & Cumulative $\%$ \\
\hline Male & 573 & 50.27 & 50.27 \\
Female & 567 & 49.73 & 100.00 \\
\hline Total & $\mathbf{1 1 4 0}$ & $\mathbf{1 0 0 . 0 0}$ & - \\
\hline
\end{tabular}

TABLE 2: Respondent race.

\begin{tabular}{lccc}
\hline Race & Frequency & $\mathbf{\%}$ & Cumulative $\%$ \\
\hline Black & 762 & 66.84 & 66.84 \\
White & 206 & 18.07 & 84.91 \\
Coloured & 116 & 10.18 & 95.09 \\
Asian & 56 & 4.91 & 100.00 \\
\hline Total & $\mathbf{1 1 4 0}$ & $\mathbf{1 0 0 . 0 0}$ & - \\
\hline
\end{tabular}

TABLE 3: Respondent age (years).

\begin{tabular}{lcccc}
\hline Youngest & Oldest & Mean & Median & Standard deviation \\
\hline 20 & 64 & 38.62 & 37.00 & 9.36 \\
\hline
\end{tabular}

results. As expected, most respondents were black people, accounting for just over two-thirds of the sample. Black and white people together made up almost $85 \%$ of the respondents.

The sample respondents ranged in age from 20 to 64 and were, on average, 38.62 years old.

\section{Descriptive statistics}

Basic measures of central tendency were calculated for the independent and dependent variables and are shown in Table 4.

For most of the items, the range was from 1-7. The mean score for leader CQ was 4.53 with a standard deviation of 1.17 . The leader CQ dimension mean scores varied from a high of 4.96 (metacognitive CQ) to a low of 4.15 (behavioural CQ). The mean score for empowering leadership was 5.12 with a standard deviation of 1.37, whilst the equivalent scores for directive leadership were 3.52 and 0.81 , respectively. It should be noted that the rating scale for directive leadership was 1-5.

\section{Reliability}

The Cronbach's coefficient alphas of all the factors exceeded 0.70 and accordingly satisfied the requirement set in the data analysis section. The actual scores are shown in Table 5 .

\section{Factorial validity}

The validity of the instruments was tested through exploratory factorial analysis. The data on leader $C Q$, empowering leadership and directive leadership were found to be factorable. The Kaiser-Meyer-Olkin measure was 0.95 for leader CQ, 0.92 for empowering leadership and 0.84 for directive leadership. Categorisation of these scores, per the guidelines noted by Dziuban and Shirkey (1974), indicates

TABLE 4: Measures of central tendency for leader cultural intelligence, empowering leadership and directive leadership.

\begin{tabular}{lcccc}
\hline Variable & Minimum & Maximum & Mean & Standard deviation \\
\hline Leader CQ (aggregate) & 1.00 & 7.00 & 4.53 & 1.17 \\
Leader metacognitive CQ & 1.00 & 7.00 & 4.96 & 1.45 \\
Leader cognitive CQ & 1.00 & 7.00 & 4.42 & 1.33 \\
Leader motivational CQ & 1.00 & 7.00 & 4.57 & 1.34 \\
Leader behavioural CQ & 1.00 & 7.00 & 4.15 & 1.40 \\
Empowering leadership & 1.00 & 7.00 & 5.12 & 1.37 \\
Directive leadership & 1.00 & 5.00 & 3.52 & 0.81
\end{tabular}

$\mathrm{CQ}$, cultural intelligence.

TABLE 5: Correlations and reliabilities for leader cultural intelligence, empowering leadership and directive leadership.

\begin{tabular}{lccc}
\hline Variable & $\begin{array}{c}\text { Empowering } \\
\text { leadership }\end{array}$ & Directive leadership & Coefficient $\boldsymbol{\alpha}$ \\
\hline Leader CQ (aggregate) & $0.64^{*}$ & $0.39^{*}$ & 0.95 \\
Leader metacognitive CQ & $0.64^{*}$ & $0.32^{*}$ & 0.93 \\
Leader cognitive CQ & $0.49^{*}$ & $0.35^{*}$ & 0.91 \\
Leader motivational CQ & $0.57^{*}$ & $0.36^{*}$ & 0.90 \\
Leader behavioural CQ & $0.45^{*}$ & $0.30^{*}$ & 0.91 \\
Empowering leadership & - & $0.45^{*}$ & 0.93 \\
Directive leadership & - & - & 0.87
\end{tabular}

$\mathrm{CQ}$, cultural intelligence.

$*, p<0.05$. 
that they are highly acceptable. The Bartlett's test of sphericity was significant for all of leader $C Q$, empowering leadership and directive leadership ( $p \leq 0.001)$. Consequently, sampling adequacy was satisfactory.

Leader CQ was found to be composed of four factors, using the rule that the number of factors is predicted by eigenvalues greater than one. This structure matched that conceptualised by Earley and Ang (2003) and Ang and Van Dyne (2008). All the measurement items for leader metacognitive, motivational and behavioural CQ loaded onto their respective factors with weights exceeding 0.50. Although all the items used to measure leader cognitive CQ loaded onto it, only $83 \%$ had a weight greater than 0.50 each. This four-factor structure of leader CQ had a declared variance of $74.38 \%$.

Empowering leadership was found to be unidimensional with all 10 measurement items loading onto it. The weight of the lowest loading item was 0.74 . The declared variance was $62.15 \%$. Although directive leadership exhibited a threefactor structure with all items having weights above 0.50 , its alpha was not increased when each of the scale items were removed; that is, the items demonstrated high internal consistency and consequently directive leadership was taken, for purposes of this study, as being unidimensional too. The declared variance of the three-factor solution was $75.90 \%$.

\section{Correlations}

Table 5 shows the correlations between the variables as well as their Cronbach's coefficient alphas.
All the correlations between the variables were significant at the $5 \%$ level. The empowering leadership relationship was strongest with leader CQ (as a composite value) and leader metacognitive CQ (both 0.64), followed by leader motivational CQ (0.57), leader cognitive CQ (0.49) and then leader behavioural CQ (0.45). The directive leadership relationship was greatest with leader CQ (as a composite value) (0.39), then leader motivational CQ (0.36), leader cognitive CQ (0.35), leader metacognitive CQ (0.32), and lastly, leader behavioural CQ (0.30).

Based on the results, $\mathrm{H}_{0}$ and $\mathrm{H} 2_{0}$ were rejected, that is, a statistically significant relationship was found to exist between leader CQ (as a composite value) and both empowering and directive leadership. $\mathrm{H}_{0}$ was rejected because the statistical strength of the relationship between leader CQ (as a composite value) and empowering leadership was significantly greater than that between leader CQ (as a composite value) and directive leadership ( $z=10.129, p<$ 0.05). As statistically significant relationships existed between each of the four leader CQ dimensions with both empowering and directive leadership, $\mathrm{H}_{0}$ and $\mathrm{H}_{0}$ were also rejected.

\section{Stepwise regression}

To investigate the effects of the independent variables in unison on the dependent variables and with particular focus on the contribution of each, stepwise regression analysis was undertaken. The results are reflected in Tables 6 and 7 .

The stepwise regression revealed that just two of the four subscales of leader CQ, metacognitive and motivational CQ, were statistically significant predictors of empowering

\begin{tabular}{|c|c|c|c|c|c|c|}
\hline Model & $R$ & $R^{2}$ & $\boldsymbol{\beta}$ & $t$-value & Sig & $f^{2}$ \\
\hline 1 & 0.64 & 0.41 & - & - & - & $0.69 \dagger$ \\
\hline (Constant) & - & - & & 18.92 & 0.00 & - \\
\hline Leader metacognitive CQ & - & - & 0.64 & 28.29 & 0.00 & - \\
\hline 2 & 0.67 & 0.45 & - & - & - & $0.82 \dagger$ \\
\hline (Constant) & - & - & - & 14.63 & 0.00 & - \\
\hline Leader metacognitive CQ & - & - & 0.47 & 16.02 & 0.00 & - \\
\hline Leader motivational CQ & - & - & 0.26 & 8.80 & 0.00 & - \\
\hline
\end{tabular}

$\dagger$, effect size $\left(R^{2}\right) /\left(1-R^{2}\right)$

$\mathrm{CQ}$, cultural intelligence; $R$, multiple correlation; $R^{2}$, proportion of variance explained; $\beta$, standardised regression coefficient; Sig, significance; $f^{2}$, the proportion of the variation accounted for by the regression line relative to the proportion not accounted for.

TABLE 7: Stepwise regression for directive leadership.

\begin{tabular}{|c|c|c|c|c|c|c|}
\hline$\overline{\text { Model }}$ & $R$ & $R^{2}$ & $\bar{\beta}$ & $t$-value & Sig & $f^{2}$ \\
\hline 1 & 0.36 & 0.13 & - & - & - & $0.15 \dagger$ \\
\hline (Constant) & - & - & - & 31.76 & 0.00 & - \\
\hline Leader motivational CQ & - & - & 0.36 & 13.17 & 0.00 & - \\
\hline 2 & 0.39 & 0.15 & - & - & - & $0.18 \dagger$ \\
\hline (Constant) & - & - & - & 28.58 & 0.00 & - \\
\hline Leader motivational CQ & - & - & 0.23 & 5.75 & 0.00 & - \\
\hline 3 & 0.39 & 0.15 & - & - & - & $0.18 \dagger$ \\
\hline (Constant) & - & - & - & 26.46 & 0.00 & - \\
\hline Leader motivational CQ & - & - & 0.19 & 4.43 & 0.00 & - \\
\hline Leader cognitive CQ & - & - & 0.16 & 3.87 & 0.00 & - \\
\hline Leader metacognitive $\mathrm{CQ}$ & - & - & 0.09 & 2.39 & 0.02 & - \\
\hline
\end{tabular}

$\dagger$, effect size $\left(R^{2}\right) /\left(1-R^{2}\right)$

$\mathrm{CQ}$, cultural intelligence; $R$, multiple correlation; $R^{2}$, proportion of variance explained; $\beta$, standardised regression coefficient; Sig, significance; $f^{2}$, the proportion of the variation accounted for by the regression line relative to the proportion not accounted for. 
leadership. It follows that $\mathrm{H}_{0}$ was not rejected because neither the cognitive nor the behavioural CQ dimensions played any role in this respect.

Leader motivational, cognitive and metacognitive CQ predicted directive leadership. As leader behavioural CQ failed to occupy a position of statistical significance in predicting directive leadership, $\mathrm{H}_{0}$ was not rejected.

\section{Discussion Outline of the results}

Correlation coefficients illustrate associations between variables, that is, they provide information on the 'strength and direction' of the relationship (Mukaka, 2012, p. 71). The significant associations that have been identified between leader CQ (as a composite value) and its dimensions with both empowering and directive leadership demonstrate that the respective variables have, at a statistical level, a recognised linear relationship. As all the correlation coefficients were positive, the implication is that when leader CQ or its dimensions increase or decrease, empowering and directive leadership levels would, similarly, record an escalation or reduction. However, statistical significance does not appraise whether the calculated associations between the variables are in fact important (Thompson, 2002). Using the guidelines of Cohen (1988), leader CQ (as a composite value) and both its metacognitive and motivational CQ dimensions were confirmed as having a large, that is, a strong practical association with empowering leadership. Leader cognitive and behavioural CQ, in turn, demonstrated a medium or moderate practical association with empowering leadership. Leader CQ (and each of its dimensions) had less of a practical relationship with directive leadership, however, in that the respective correlation coefficients all tended towards the lower end of Cohen's (1988) medium range. Empowering leaders are also considered to be more culturally intelligent than directive leaders, as borne out by the statistically significant difference between the respective strengths of the empowering leadership and directive leadership relationships with leader CQ.

When applying all the leader CQ dimensions together, just metacognitive and motivational CQ were found to be statistically significant predictors of empowering leadership and, together, accounted for $45 \%$ of its variance. Individually, the metacognitive CQ dimension was the stronger of the two as evidenced by its higher $\beta$. Apart from behavioural CQ, all the leader CQ dimensions contributed to forecasting directive leadership at a statistically significant level despite only being able to explain $15 \%$ of the variance therein. The large practical significance of the stepwise regression result for empowering leadership was evidenced by its $f$ statistic of 0.82 . In comparison, the result for directive leadership held only a medium practical significance, given its $f^{2}$ statistic of 0.18 .

Research efforts to understand the relationship between leader CQ and leadership styles have already been discussed in the literature review section of this article. As there is an apparent absence of empirical insights addressing the relationship between leader CQ and both empowering and directive leadership, it could be beneficial to identify other leadership styles that are similar to the aforementioned as a basis for contextualising the findings of this study. Hassan et al. (2016), as an example, incorporate empowering leadership under the transformational leadership style in their typology. This, however, should be read in conjunction with Sharma and Kirkman (2015) who argue that empirical evidence supports the existence of empowering and transformational leadership as being distinct from one another. Likewise, although Kim and Beehr (2017) state that empowering and transformational leadership might be conceptually comparable, they do remark that empowering leadership remains discrete in terms of its behaviours. Hence, it may not be appropriate to directly compare the results of this study with others that have explored the relationship between leader $\mathrm{CQ}$ and transformational leadership. Concerning directive leadership, Yun, Faraj and Sims (2005) assert that it is theoretically similar to the autocratic style. As discussed earlier, Eken et al. (2014) found that no empirical relationship between leader CQ (and its dimensions) and autocratic leadership existed. This study, by contrast, revealed that leader composite CQ and each of its dimensions did have a moderate association with directive leadership.

\section{Theoretical implications}

This study results in three important theoretical implications. Firstly, evidence of the four-factor structure of CQ, per Earley and Ang (2003), has been provided. This finding is consistent with that of Mahembe and Engelbrecht (2014) who confirmed the construct validity of the CQS within the South African context. Secondly, the nature of the leader CQ relationships with empowering leadership and directive leadership has been determined. The leader CQ dimensions that associated the most with and best predicted empowering and directive leadership have also been identified. The CQ and leadership nomological networks have therefore been expanded. Finally, the outputs contribute to satisfying the recent calls by scholars, such as Brannen (2016) and Clark and Waldron (2016), for empirical insights on leader CQ and its relationship with leadership styles other than transformational, as well as that by Sharma and Kirkman (2015) for research into the antecedents of different leadership styles, particularly empowering leadership.

\section{Practical implications}

This study holds value for both the appointment and growth of leaders. Organisations recruiting for either international assignments or domestic operations in culturally diverse societies, such as South Africa, may use the results to better inform their selections. Where the cultural profiles of subordinates dictate a preference for empowerment, human resource practitioners should concentrate on selecting those leaders evidencing higher levels of $C Q$ in general and, especially, metacognitive and motivational CQ. Similarly, because these two dimensions act as important antecedents 
of empowering leadership, they should form an integral component of leadership development programmes. To this end, efforts ought to be centred on enhancing the ability of leaders to map out an optimal methodology by which to approach cross-cultural interactions and for how best to modify their assumptions, during such interfaces, should these conflict with reality. Likewise, stimulating leaders' selfbelief regarding their success in cross-cultural engagement should be promoted.

Human resource professionals may use leaders' levels of motivational, cognitive and, to a lesser extent, metacognitive $\mathrm{CQ}$ to gauge the probability that leaders will display directive leadership. They are, however, reminded that these leader CQ dimensions explain just a limited amount $(15 \%)$ of the variance in this leadership style. Hence, they may want to augment the use of leader CQ with other antecedents of directive leadership, such as leadership level (Oshagbemi, 2008).

\section{Limitations and recommendations}

The primary limitation of this research is that it was based on a convenience sample. The scope for generalisation of the results to the population as a whole could thus be limited. However, as the participating organisations reflect broad diversity, both in terms of their size and the industry type in which they operate, and the respondents, in each of them, were chosen randomly, these factors do, to some extent, mitigate this. Another limitation is that, being cross-sectional, it was not possible for the study to produce any insights as to causality from the research outputs. Although a longitudinal or experimental design may have improved the results, it should be noted, as pointed out previously, that crosssectional research is well suited for correlative studies such as this one. The exclusive use of observer-based perceptions may also have restricted the study. Hence, additional data, such as that from self-reporting, and objective measures of behaviour, should be included in future studies. This may allow for triangulation of results. It would also be important to consider whether the results of this research may be replicated in countries whose citizens are culturally distinct from those of South Africa or even in jurisdictions where the culture of the population is homogeneous. Finally, the introduction of supplementary variables such as leadership level, which is an important predictor in the use of directive leadership (Oshagbemi, 2008), may improve the accuracy of the research.

\section{Conclusion}

Leadership style is a function of leader CQ; however, the nature and magnitude of the role played by leader CQ varies considerably between leadership styles in general and, particularly, in terms of both the statistical and practical significance thereof. Although leader composite CQ was associated with both empowering and directive leadership, the strength of the statistical relationship was not only greater in the case of empowering leadership but was also large in terms of practical relevance. The practical relevance of the relationship with directive leadership was merely moderate. In considering interventions, emphasis should be placed on the metacognitive and motivational aspects of leader CQ because they are the most important dimensions related to empowering leadership. On the other hand, the motivational, cognitive and metacognitive leader CQ dimensions should be concentrated on in the context of directive leadership. The question that this study sought to address has therefore been answered and the research problem solved.

\section{Acknowledgements Competing interests}

The authors declare that they have no competing interests in writing this article.

\section{Authors' contributions}

A.S. conducted the literature review, analysed the data and drafted the manuscript. R.S. provided conceptual and design input and commentary on the manuscript drafts.

\section{References}

Ababneh, R.I. (2016, March 7-9). Successful leadership components: A qualitative approach. Paper presented at the WEI International Academic Conference, Barcelona.

Adeel, A., \& Pengcheng, Z. (2016). How are they gaining such positions? An examination of antecedents of informal leadership at organizations. European Journal of Business and Management, 8(2), 81-89.

Ahearne, M., Mathieu, J., \& Rapp, A. (2005). To empower or not to empower your sales force? An empirical examination of the influence of leadership empowerment behavior on customer satisfaction and performance. Journal of Applied Psychology, 90(5), 945-955. https://doi.org/10.1037/0021-9010.90.5.945

Alon, I., \& Higgins, J.M. (2005). Global leadership success through emotional and cultural intelligences. Business Horizons, 48(6), 501-512. https://doi. org/10.1016/j.bushor.2005.04.003

Amundsen, S., \& Martinsen, $\varnothing$. (2014). Self-other agreement in empowering leadership: Relationships with leader effectiveness and subordinates' job satisfaction and turnover intention. The Leadership Quarterly, 25(4), 784-800. https://doi.org/10.1016/j.leaqua.2014.04.007

Amundsen, S., \& Martinsen, $\varnothing$. (2015). Linking empowering leadership to job satisfaction, work effort, and creativity: The role of self-leadership and psychological empowerment. Journal of Leadership \& Organizational Studies, 22(3), 304-323. https://doi.org/10.1177/1548051814565819

Ang, S., \& Inkpen, A.C. (2008). Cultural intelligence and offshore outsourcing success: A framework of firm-level intercultural capability. Decision Sciences, 39(3), 337358. https://doi.org/10.1111/j.1540-5915.2008.00195.x

Ang, S., \& Van Dyne, L. (2008). Conceptualization of cultural intelligence: Definition, distinctiveness, and nomological network. In S. Ang \& L. Van Dyne (Eds.), Handbook on cultural intelligence: Theory, measurement and applications (pp 3-15). Armonk, NY: M.E. Sharpe.

Ang, S., Van Dyne, L., Koh, C., Ng, K.Y., Templer, K.J., Tay, C., et al. (2007). Cultural intelligence: Its measurement and effects on cultural judgment and decision making, cultural adaptation and task performance. Management \& Organization Review, 3(3), 335-371. https://doi.org/10.1111/j.1740-8784.2007.00082.x

Ang, S., Van Dyne, L., \& Rockstuhl, T. (2015). Cultural intelligence: Origins, conceptualization, evolution, and methodological diversity. In M.J. Gelfand, C. Chiu, \& Y. Hong (Eds.), Handbook of advances in culture psychology (pp. 273-323). New York: Oxford University Press.

Ang, S., Van Dyne, L., \& Tan, M.L. (2011). Cultural intelligence. In R.J. Sternberg, \& S.B. Kaufman (Eds.), The Cambridge handbook of intelligence (pp. 582-602). New York: Cambridge University Press.

Arnold, J.A., Arad, S., Rhoades, J.A., \& Drasgow, F. (2000). The empowering leadership questionnaire: The construction and validation of a new scale for measuring leader behaviors. Journal of Organizational Behavior, 21(3), 249-269. https://doi org/10.1002/(SICI)1099-1379(200005)21:3\%3C249::AID-JOB10\%3E3.0.CO;2-\#

Avolio, B.J., Walumbwa, F.O., \& Weber, T.J. (2009). Leadership: Current theories, research, and future directions. Annual Review of Psychology, 60, 421-449. https://doi.org/10.1146/annurev.psych.60.110707.163621

Bass, M., \& Bass, R. (2008). The Bass handbook of leadership (4th ed.). New York: Free Press.

Biemann, T., Kearney, E., \& Marggraf, K. (2015). Empowering leadership and managers' career perceptions: Examining effects at both the individual and team level. The Leadership Quarterly, 26(5), 775-789. https://doi.org/10.1016/j.leaqua.2015. 03.003 
Blunt, P., \& Jones, M. L. (1997). Exploring the limits of western leadership theory in East Asia and Africa. Personnel Review, 26(1/2), 6-23. https://doi. East Asia and Africa. Person
org/10.1108/00483489710157760

Bobbio, A., Bellan, M., \& Manganelli, A.M. (2012). Empowering leadership, perceived organizational support, trust, and job burnout for nurses: A study in an Italian general hospital. Health Care Management Review, 37(1), 77-87. https://doi. org/10.1097/HMR.0b013e31822242b2

Bolden, R. (2004). What is leadership? Exeter: Leadership South West.

Brannen, J.C. (2016). The relationship between cultural intelligence and transformational leadership: A study of people leaders. Unpublished doctoral dissertation, University of the Rockies, Denver, CO.

Brauckmann, S., \& Pashiardis, P. (2011). A validation study of the leadership styles of a holistic leadership theoretical framework. International Journal of Educational Management, 25(1), 11-32. https://doi.org/10.1108/09513541111100099

Caldwell, J. (2015). Leading globally, thinking interculturally: Developing global characteristics. Journal of Business Diversity, 15(1), 55-59.

Charoensukmongkol, P. (2016). Cultural intelligence and export performance of small and medium enterprises in Thailand: Mediating roles of organizational capabilities. and medium enterprises in Thailand: Mediating roles of organizational capabilities.
International Small Business Journal, 34(1), 105-122. https://doi. International Small Business
org/10.1177/0266242614539364

Clark, K.D., \& Waldron, T. (2016). Predictors of leadership behavior in early career white-collar professionals: The roles of personal characteristics and career context. Journal of Leadership \& Organizational Studies, 23(1), 27-38. https://doi. context. Journal of Leadership \& Orga
org/10.1177/1548051815587759

Cohen, J. (1988). Statistical power analysis for behavioral sciences. Mahwah, NJ: Lawrence Erlbaum Associates.

Conway, J.M. (2000). Managerial performance development constructs and personality correlates. Human Performance, 13(1), 23-46. https://doi. org/10.1207/S15327043HUP1301_2

Coovert, M.D., \& McNelis, K. (1988). Determining the number of common factors in factor analysis: A review and program. Educational and Psychological Measurement, 48(3), 687-692. https://doi.org/10.1177/0013164488483012

Costello, A.B., \& Osborne, J.W. (2005). Best practices in exploratory factor analysis: Four recommendations for getting the most from your analysis. Practical Assessment, Research \& Evaluation, 10(7), 1-9.

Courtney, M.G.R. (2013). Determining the number of factors to retain in EFA: Using the SPSS R-menu v2.0 to make more judicious estimations. Practical Assessment, Research \& Evaluation, 18(8), 1-14.

Dewettinck, K., \& van Ameijde, M. (2011). Linking leadership empowerment behaviour to employee attitudes and behavioural intentions: Testing the mediating role of psychological empowerment. Personnel Review, 40(3), 284-305. https://doi. org/10.1108/00483481111118621

Dickson, M.W., Castaño, N., Magomaeva, A., \& Den Hartog, D.N. (2012) Conceptualizing leadership across cultures. Journal of World Business, 47, 483Conceptualizing leadership across cultures. Jou
492. https://doi.org/10.1016/j.jwb.2012.01.002

Doh, J.P., \& Quigley, N.R. (2014). Responsible leadership and stakeholder management: Influence pathways and organizational outcomes. The Academy of Management Perspectives, 28(3), 255-274. https://doi.org/10.5465/amp.2014.0013

Dolatabadi, H.R., \& Safa, M. (2011). The effect of directive and participative leadership style on employees' commitment to service quality. Journal of Business and Management, 4(2), 1-13.

Du Plessis, Y. (2011). Cultural intelligence as managerial competence. Alternation, 18(1), 28-46.

Dziuban, C.D., \& Shirkey, E.C. (1974). When is a correlation matrix appropriate for factor analysis? Psychological Bulletin, 81(6), 358-361. https://doi.org/10.1037/h0036316

Earley, P.C., \& Ang, S. (2003). Cultural intelligence: Individual interactions across cultures. Redwood City, CA: Stanford University Press.

Eisenberg, J., Lee, H.J., Bruck, F., Brenner, B., Claes, M.T., Mironski, J., et al. (2013). Can business schools make students culturally competent? Effects of cross-cultural management courses on cultural intelligence. Academy of Management Learning management courses on cultural intelligence. Academy of Management
\& Education, 12(4), 603-621. https://doi.org/10.5465/amle.2012.0022

Eken, I., Özturgut, O., \& Craven, A.E. (2014). Leadership styles and cultural intelligence. Journal of Leadership, Accountability and Ethics, 11(3), 154-165.

Elenkov, D.S., \& Manev, I.M. (2009). Senior expatriate leadership's effects on innovation and the role of cultural intelligence. Journal of World Business, 44(4), 357-369. https://doi.org/10.1016/j.jwb.2008.11.001

Ellis, S.M., \& Steyn, H.S. (2003). Practical significance (effect sizes) versus or in combination with statistical significance ( $p$-values). Management Dynamics, 12(4), 51-53.

Ensley, M.D., Hmieleski, K.M., \& Pearce, C.L. (2006). The importance of vertical and shared leadership within new venture top management teams: Implications fo the performance of startups. The Leadership Quarterly, 17(3), 217-231. https:// doi.org/10.1016/j.leaqua.2006.02.002

Erkutlu, H., \& Chafra, J. (2015). Empowering leadership and organizational job embeddedness: The moderating roles of task interdependence and organizational politics. Procedia - Social and Behavioral Sciences, 210, 3-10. https://doi. org/10.1016/j.sbspro.2015.11.321

Esen, E. (2015). Leadership styles in organizations participating in the UN global compact. Advances in Sustainability and Environmental Justice, 16, 159-173. https://doi.org/10.1108/S2051-503020140000016022

Esteves, T., \& Lopes, M.P. (2017). Leading to crafting: The relation between leadership perception and nurses' job crafting. Western Journal of Nursing Research, 39(6),
$763-783$. https://doi.org/10.1177/0193945916659507
Faraj, S., \& Sambamurthy, V. (2006). Leadership of information systems development projects. Transactions on Engineering Management, 53(2), 238-249. https://doi. projects. Transactions on Engineeri
org/10.1109/TEM.2006.872245

Field, A. (2012). Discovering statistics using IBM SPSS statistics (4th ed.). Thousand Oaks, CA: Sage.

Fry, L.W., Vitucci, S., \& Cedillo, M. (2005). Spiritual leadership and army transformation: Theory, measurement, and establishing a baseline. The Leadership Quarterly, 16(5), 835-862. https://doi.org/10.1016/j.leaqua.2005.07.012

Fung, K., \& Lo, T. (2017). An integrative clinical approach to cultural competent psychotherapy. Journal of Contemporary Psychotherapy, 47(2), 65-73. https:// doi.org/10.1007/s10879-016-9341-8

Galanou, E. (2009). Helping middle managers take effective action: An empowering leadership style. Archives of Economic History, 21(1), 213-239.

Gkorezis, P. (2016). Principal empowering leadership and teacher innovative behavior: A moderated mediation model. International Journal of Educational Management, 30(6), 1030-1044. https://doi.org/10.1108/IJEM-08-2015-0113

Golla, E., \& Johnson, R. (2013). The relationship between transformational and transactional leadership styles and innovation commitment and output at commercial software companies. The Business Review, 21(1), 337-343.

Govender, K. (2016). Empowering leadership and municipal service delivery: A case study of a metropolitan municipality in South Africa. International Journal of Public Administration, 4O(5), 427-433. https://doi.org/10.1080/01900692.2015.1127964

Groves, K.S., \& Feyerherm, A.E. (2011). Leader cultural intelligence in context: Testing the moderating effects of team cultural diversity on leader and team performance. Group \& Organization Management, 36(5), 535-566. https://doi. org/10.1177/1059601111415664

Hair, J.F., Jr., Black, W.C., Babin, B.J., \& Anderson, R.E. (2010). Multivariate dato analysis (7th ed.). Upper Saddle River, NJ: Prentice Hall.

Hakimi, N., van Knippenberg, D., \& Giessner, S. (2010). Leader empowering behaviour: The leader's perspective. British Journal of Management, 21(3), 701-716. https:// doi.org/10.1111/j.1467-8551.2010.00703.x

Hanges, P.J., Aiken, J.R., Park, J., \& Su, J. (2016). Cross-cultural leadership: Leading around the world. Current Opinion in Psychology, 8(1), 64-69. https://doi. org/10.1016/j.copsyc.2015.10.013

Harris, T.B., Li, N., Boswell, W.R., Zhang, X., \& Xie, Z. (2014). Getting what's new from newcomers: Empowering leadership, creativity, and adjustment in the newcomers: Empowering leadership, creativity, and
socialization context. Personnel Psychology, 67(3), 567-604.

Hassan, H., Asad, S., \& Hoshino, Y. (2016). Determinants of leadership style in big five personality dimensions. Universal Journal of Management, 4(4), 161-179. https://doi.org/10.13189/ujm.2016.040402

Higgs, M. (2003). How can we make sense of leadership in the 21st century? Leadership \& Organization Development Journal, 24(5), 273-284. https://doi. org/10.1108/01437730310485798

Hinrichs, A.T. (2011). Motivation to lead: Examining its antecedents and consequences in a team context. Unpublished doctoral dissertation, Texas A\&M University, College Station, TX.

Hmieleski, K.M., \& Ensley, M.D. (2007). A contextual examination of new venture performance: Entrepreneur leadership behavior, top management team heterogeneity, and environmental dynamism. Journal of Organizational Behavior 28(7), 865-889. https://doi.org/10.1002/job.479

Holten, A.L., Bøllingtoft, A., \& Wilms, I. (2015). Leadership in a changing world: Developing managers through a teaching and learning programme. Management Decision, 53(5), 1107-1124. https://doi.org/10.1108/MD-10-2014-0617

Horner, M. (1997). Leadership theory: Past, present and future. Team Performance Management: An International Journal, 3(4), 270-287. https://doi. org/10.1108/13527599710195402

House, R., Javidan, M., \& Dorfman, P. (2001). Project GLOBE: An introduction. Applied Psychology: An International Review, 50(4), 489-505. https://doi. org/10.1111/1464-0597.00070

Hwang, S.J., Quast, L.N., Center, B.A., Chung, C.N., Hahn, H., \& Wohkittel, J. (2015). The impact of leadership behaviours on leaders' perceived job performance across cultures: Comparing the role of charismatic, directive, participative, and supportive leadership behaviours in the U.S and four Confucian Asian countries.
Human Resource Development International, 18(3), 259-277. https://doi.org/10. Human Resource Development Inte
1080/13678868.2015.1036226

Ismail, A.M., Reza, R., \& Mahdi, S. (2012). Analysis [sic] the relationship between cultural intelligence and transformational leadership. International Journal of Business and Social Science, 3(14), 252-261.

Iszatt-White, M., Graham, C., Kelly, S., Randall, D., \& Rouncefield, M. (2011). Leadership in post compulsory education. London: Continuum International Publishing Group.

Javidan, M., \& Dastmalchian, A. (2009). Managerial implications of the GLOBE project: A study of 62 societies. Asia Pacific Journal of Human Resources, 47(1), 41-58. https://doi.org/10.1177/1038411108099289

Jogulu, U.D. (2010). Culturally-linked leadership styles. Leadership \& Organization Development Journal, 31(8), 705-719. https://doi.org/10.1108/ 01437731011094766

Joo, B., Park, J.G., \& Lim, T. (2016). Structural determinants of psychological well-being for knowledge workers in South Korea. Personnel Review, 45(5), 1069-1086. https://doi.org/10.1108/PR-01-2015-0011

Kalaluhi, S. (2013). Leadership in context: The moderating effect of follower need for autonomy on directive leadership style, empowering leadership style, and leader effectiveness in volunteer organizations. In Global Conference on Business and
Finance Proceedings (pp. 139-143). Hilo, HI: The Institute for Business and Finance Proceedings
Finance Research. 
Keung, E.K., \& Rockinson-Szapkiw, A.J. (2013). The relationship between transformational leadership and cultural intelligence: A study of international school leaders. Journal of Educational Administration, 51(6), 836-854. https:// school leaders. Journal of Educational
doi.org/10.1108/JEA-04-2012-0049

Kim, H., \& Yukl, G. (1995). Relationships of managerial effectiveness and advancement to self-reported and subordinate-reported leadership behaviors from the multilinkage model. The Leadership Quarterly, 6(3), 361-377. https://doi. linkage model. The Leadership
org/10.1016/1048-9843(95)90014-4

Kim, M., \& Beehr, T.A. (2017). Self-efficacy and psychological ownership mediate the effects of empowering leadership on both good and bad employee behaviors. Journal of Leadership \& Organizational Studies. https://doi.org/10.1177/ 1548051817702078

Klenke, K. (2009). Trilogy of the leader's mind: Emotional, cultural and spiritual intelligences. Journal of Management Systems, 21(1), 1-30.

Kurpis, L.V. (2012). Empirical investigation of select personality, attitudinal, and experience-based antecedents of cultural intelligence in undergraduate business students. Journal of Learning in Higher Education, 8(1), 47-57.

Kwak, W.J., \& Jackson, C.L. (2015). Relationship building in empowering leadership processes: A test of mediation and moderation. Journal of Management \& Organization, 21(4), 369-387. https://doi.org/10.1017/jmo.2015.11

Landis, E.A., Hill, D., \& Harvey, M.R. (2014). A synthesis of leadership theories and styles. Journal of Management Policy and Practice, 15(2), 97-100.

Lazaraton, A. (1991). Power, effect size, and second language research: A researcher comments. TESOL Quarterly, 25(4), 759-762. https://doi.org/10.2307/3587102

Lee, I.A., \& Preacher, K.J. (2013). Calculation for the test of the difference between two dependent correlations with one variable in common [Computer software]. Retrieved July 18 2016, from http://quantpsy.org/corrtest/corrtest2.htm

Lee, J., Lee, H., \& Park, J. (2014). Exploring the impact of empowering leadership on knowledge sharing, absorptive capacity and team performance in IT service. Information Technology \& People, 27(3), 366-386. https://doi.org/10.1108/ITP10-2012-0115

Lee, L.Y., Veasna, S., \& Wu, W.Y. (2013). The effects of social support and transformational leadership on expatriate adjustment and performance: The moderating roles of socialization experience and cultural intelligence. Career Development International, 18(4), 377-415. https://doi.org/10.1108/CDI-062012-0062

Li, M., Liu, W., Han, Y., \& Zhang, P. (2016). Linking empowering leadership and changeorientated organizational citizenship behavior: The role of thriving at work and autonomy orientation. Journal of Organizational Change Management, 29(5), 732-750. https://doi.org/10.1108/JOCM-02-2015-0032

Livermore, D. (2010). Leading with cultural intelligence: The new secret to success. New York: AMACOM.

Lorinkova, N.M., Pearsall, M.J., \& Sims, H.P., Jr. (2013). Examining the differential longitudinal performance of directive versus empowering leadership in teams. Academy of Management Journal, 56(2), 573-596. https://doi.org/10.5465/ amj.2011.0132

Maggitti, P.G., Slay, H., \& Clark, K.D. (2010). Leadership in hypercrisis: Leading in the face of a shaken culture. Kravis Leadership Institute, Leadership Review, 10, 48-67.

Magnusson, P., Westjohn, S.A., Semenov, A.V., Randrianasolo, A.A., \& Zdravkovic, S. (2013). The role of cultural intelligence in marketing adaptation and export performance. Journal of International Marketing, 21(4), 44-61. https://doi. org/10.1509/jim.13.0055

Mahembe, B., \& Engelbrecht, A.S. (2014). A preliminary study to assess the construct validity of a cultural intelligence measure on a South African sample. SA Journal of Human Resource Management, 12(1), 1-8. https://doi.org/10.4102/sajhrm. v12i1.558

Martin, S.L., Liao, H. \& Campbell, E.M. (2013). Directive versus empowering leadership: A field experiment comparing impacts on task proficiency and
proactivity. Academy of Management Journal, 56(5), 1372-1395. https://doi. proactivity. Academy of Manag
org/10.5465/amj.2011.0113

McDonough, E.F., III, \& Barczak, G. (1991). Speeding up new product development: The effects of leadership style and source of technology. Journal of Product
Innovation Management,
8(3), 203-211. https://doi.org/10.1016/0737Innovation Manag

Mohamed, L.M. (2016). Assessing the effects of transformational leadership: A study on Egyptian hotel employees. Journal of Hospitality and Tourism Management, 27, 49-59. https://doi.org/10.1016/j.jhtm.2016.04.001

Muczyk, J.P., \& Reimann, B.C. (1987). The case for directive leadership. The Academy of Management Executive, 1(4), 301-311. https://doi.org/10.5465/ AME.1987.4275646

Mukaka, M.M. (2012). Statistics corner: A guide to appropriate use of correlation coefficient in medical research. Malawi Medical Journal, 24(3), 69-71.

Ng, K., Van Dyne, L., \& Ang, S. (2012). Cultural intelligence: A review, reflections, and recommendations for future research. In A.M. Ryan, F.T.L. Leong, \& F.L. Oswald (Eds.), Conducting multinational research: Applying organizational psychology in the workplace (pp. 29-58). Washington, DC: American Psychological Association.

Ng, K.Y., \& Earley, P.C. (2006). Culture + intelligence. Group \& Organization Management, 31(1), 4-19. https://doi.org/10.1177/1059601105275251

Ng, K.Y., Van Dyne, L., \& Ang, S. (2009). From experience to experiential learning: Cultural intelligence as a learning capability for global leader development Academy of Management Learning \& Education, 8(4), 511-526. https://doi. org/10.5465/AMLE.2009.47785470

Northouse, P.G. (2013). Leadership: Theory and practice (6th ed.). Thousand Oaks, CA: Sage.
Offermann, L.R., \& Phan, L.U. (2008). Culturally intelligent leadership for a diverse world. In R.E. Riggio, S.E. Murphy, \& F.J. Pirozzolo (Eds.), Multiple intelligences and leadership (pp. 187-214). Mahwah, NJ: Lawrence Erlbaum Associates.

Osborne, J.W., \& Costello, A.B. (2009). Best practices in exploratory factor analysis: Four recommendations for getting the most from your analysis. Pan-Pacific Management Review, 12(2), 131-146.

Oshagbemi, T. (2008). The impact of personal and organisational variables on the leadership styles of managers. The International Journal of Human Resource Management, 19(10), 1896-1910. https://doi.org/10.1080/09585190802324130

Ott, D.L., \& Michailova, S. (2016). Cultural intelligence: A review and new research avenues. International Journal of Management Reviews. https://doi.org/10.1111/ ijmr.12118

Pallent, J. (2011). SPSS survival manual (4th ed.). Sydney: Allen \& Unwin.

Parham, J.B., Lewis, C.C., Fretwell, C.E., Irwin, J.G., \& Schrimsher, M.R. (2015). Influences on assertiveness: Gender, national culture, and ethnicity. Journal of Management Development, 34(4), 421-439. https://doi.org/10.1108/JMD-092013-0113

Paulienè, R. (2012). Transforming leadership styles and knowledge sharing in a multicultural context. Business, Management and Education, 10(1), 91-109. multicultural context. Business, Manage
https://doi.org/10.3846/bme.2012.08

Pearce, C.L., \& Sims, H.P., Jr. (2002). Vertical versus shared leadership as predictors of the effectiveness of change management teams: An examination of aversive, directive, transactional, transformational, and empowering leader behaviors. Group Dynamics: Theory, Research, and Practice, 6(2), 172-197. https://doi. Group Dynamics: Theory, Resear
org/10.1037/1089-2699.6.2.172

Pearce, C.L., Sims, H.P., Jr., Cox, J.F., Ball, G., Schnell, E., Smith, K.A., et al. (2003). Transactors, transformers and beyond: A multi-method development of a theoretical typology of leadership. Journal of Management Development, 22(4), 273-307. https://doi.org/10.1108/02621710310467587

Peng, A.C., Van Dyne, L., \& Oh, K. (2015). The influence of motivational cultura intelligence on cultural effectiveness based on study abroad: The moderating role of participant's [sic] cultural identity. Journal of Management Education, 39(5), 572-596. https://doi.org/10.1177/1052562914555717

Perkins, K.M. (2013). 'Investation' ... an original leadership concept. Nursing Management, 44(4), 35-39. https://doi.org/10.1097/01.numa.0000428200.29636.5a

Peterson, R.S. (1997). A directive leadership style in group decision making can be both virtue and vice: Evidence from elite and experimental groups. Journal of Personality and Social Psychology, 72(5), 1107-1121. https://doi. org/10.1037/0022-3514.72.5.1107

Ramsey, J.R., \& Lorenz, M.P. (2016). Exploring the impact of cross-cultural management education on cultural intelligence, student satisfaction, and commitment. Academy of Management Learning \& Education, 15(1), 79-99. https://doi. org/10.5465/amle.2014.0124

Raub, S., \& Robert, C. (2012). Empowerment, organizational commitment, and voice behavior in the hospitality industry: Evidence from a multinational sample. Cornell Hospitality Quarterly, 54(2), 136-148. https://doi. org/10.1177/1938965512457240

Robinson, J.L. (2016). Connecting leadership and learning: Do versatile learners make connective leaders? Higher Learning Research Communications, 6(1), 1-16.

Rockstuhl, T., Seiler, S., Ang, S., Van Dyne, L., \& Annen, H. (2011). Beyond general intelligence (IQ) and emotional intelligence (EQ): The role of cultural intelligence (CQ) on cross-border leadership effectiveness in a globalized world. Journal of
Social Issues, 67(4), 825-840. https://doi.org/10.1111/j.1540-4560.2011.01730.x

Sagie, A. (1997). Leader direction and employee participation in decision making: Contradictory or compatible practices. Applied Psychology: An International Review, 46(4), 387-452. https://doi.org/10.1111/j.1464-0597.1997.tb01244.x

Sauer, S.J. (2011). Taking the reins: The effects of new leader status and leadership style on team performance. Journal of Applied Psychology, 96(3), 574-587. https://doi.org/10.1037/a0022741

Schreier, C., \& Kainzbauer, A. (2016). Cultural intelligence at work: A case study from Thailand. In C. Barmeyer \& P. Franklin (Eds.), Intercultural management: A casebased approach to achieving complementarity and synergy (pp. 174-183). New York: Palgrave Macmillan.

Sharma, P.N., \& Kirkman, B.L. (2015). Leveraging leaders: A literature review and future lines of inquiry for empowering leadership research. Group \& Organization Management, 4O(2), 193-237. https://doi.org/10.1177/1059601115574906

Shaughnessy, J.J., Zechmeister, E.B., \& Zechmeister, J.S. (2012). Research methods in psychology (9th ed.). New York: McGraw-Hill.

Sims, H.P., Jr., Faraj, S., \& Yun, S. (2009). When should a leader be directive or empowering? How to develop your own situational theory of leadership. Business Horizons, 52(2), 149-158. https://doi.org/10.1016/j.bushor.2008.10.002

Snaebjornsson, I.M., \& Edvardsson, I.R. (2013). Gender, nationality and leadership style: A literature review. International Journal of Business and Management, 8(1), 89-103.

Somech, A. (2005). Directive versus participative leadership: Two complementary approaches to managing school effectiveness. Education Administration Quarterly, 41(5), 777-800. https://doi.org/10.1177/0013161X05279448

Statistics South Africa. (2016). Quarterly labour force survey. Retrieved 1 November 2016 from http://www.statssa.gov.za/publications/P0211/P02111stQuarter2016.pdf

Steers, R.M., Sanchez-Runde, C., \& Nardon, L. (2012). Leadership in a global context: New directions in research and theory development. Journal of World Business, 47, 479-482. https://doi.org/10.1016/j.jwb.2012.01.001

Steiger, J.H. (1980). Tests for comparing elements of a correlation matrix. Psychological Bulletin, 87(2), 245-251. https://doi.org/10.1037/0033-2909.87.2.245 
Sternberg, R.J., \& Detterman, D.J. (1986). What is intelligence? Contemporary viewpoints on its nature and definition. Norwood, NJ: Ablex.

Sternberg, R.J., \& Grigorenko, E.L. (2006). Cultural intelligence and successful intelligence. Group \& Organization Management, 31(1), 27-39. https://doi. org $/ 10.1177 / 1059601105275255$

Strydom, S.C., \& van Eeden, R. (2013). Dimensions of job satisfaction identified among South African black middle-level managers: A qualitative investigation. Journal of Psychology in Africa, 23(4), 579-584.

Tekleab, A.G., Sims, H.P., Jr., Yun, S., Tesluk, P.E., \& Cox, J. (2008). Are we on the same page? Effects of self-awareness of empowering and transformational leadership. Journal of Leadership \& Organizational Studies, 14(3), 185-201. https://doi. org/10.1177/1071791907311069

Thomas, D.C. (2006). Domain and development of cultural intelligence: The importance of mindfulness. Group \& Organization Management, 31(1), 78-99. https://doi.org/10.1177/1059601105275266

Thomas, D.C., Elron, E., Stahl, G., Ekelund, B.Z., Ravlin, E.C., Cerdin, J., et al. (2008) Cultural intelligence: Domain and assessment. International Journal of Cross Cultural Management, 8(2), 123-143. https://doi.org/10.1177/1470595808091787

Thomas, D.C., \& Inkson, K. (2005). Cultural intelligence: People skills for a global workplace. Consulting to Management, 16(1), 5-9.

Thompson, B. (2002). 'Statistical', 'practical', and 'clinical': How many kinds of significance do counselors need to consider? Journal of Counseling \& Development, 80(1), 64-71. https://doi.org/10.1002/j.1556-6678.2002. tb00167.x

Vanderpal, G. (2014). Global leadership, IQ and global quotient. Journal of Management Policy and Practice, 15(5), 120-134.

Van Dyne, L., Ang, S., \& Koh, C. (2008). Development and validation of the CQS: The cultural intelligence scale. In S. Ang \& L. Van Dyne (Eds.), Handbook of cultura intelligence: Theory, measurement, and applications (pp. 16-38). New York: M.E. Sharpe.

Van Dyne, L., Ang, S., \& Livermore, D. (2010). Cultural intelligence: A pathway for leading in a rapidly globalizing world. In K. Hannum, B.B. McFeeters, \& L. Booysen (Eds.), Leading across differences (pp. 131-138). San Francisco, CA: Pfeiffer.

Van Dyne, L., Ang, S., \& Nielsen, T.M. (2008). Cultural intelligence. In S.R. Clegg \& J.R Bailey (Eds.), International encyclopedia of organization studies (pp. 345-350). Thousand Oaks, CA: Sage.
Van Dyne, L., Ang, S., Ng, K.Y., Rockstuhl, T., Tan, M.L., \& Koh, C. (2012). Sub-dimensions of the four factor model of cultural intelligence: Expanding the conceptualization and measurement of cultural intelligence. Social and Personality Psychology Compass, 6(4), 295-313. https://doi.org/10.1111/j.1751-9004.2012.00429.x

Vie, O.E., \& Vie, G.A. (2011). The relationship between personality of leaders and team effectiveness. Scandinavian Journal of Organizational Psychology, 3(1), 18-25.

Viggiano, E. (2016). The role of cultural intelligence in cyber warfare. In D.T. Zlateva \& V.A. Greiman (Eds.), Proceedings of the 11th International Conference on Cyber Warfare and Security (pp. 415-422). Boston, MA: Academic Conferences and Publishing International.

Wendt, H., Euwema, M.C., \& van Emmerik, I.J.H. (2009). Leadership and team cohesiveness across cultures. The Leadership Quarterly, 20(3), 358-370. https:// doi.org/10.1016/j.leaqua.2009.03.005

Yoon, H.J. (2012). Predicting employee voice, behavior: An exploration of the roles of empowering leadership, power distance, organizational learning capability, and sense of empowerment in Korean organizations. Unpublished doctoral dissertation, University of Minnesota, Minneapolis, MN.

Yun, S., Cox, J., \& Sims, H.P., Jr. (2006). The forgotten follower: A contingency model of leadership and follower self-leadership. Journal of Managerial Psychology, 21(4), 374-388. https://doi.org/10.1108/02683940610663141

Yun, S., Cox, J., Sims, H.P., Jr., \& Salam, S. (2007). Leadership and teamwork: The effects of leadership and job satisfaction on team citizenship. International Journal of Leadership Studies, 2(3), 171-193.

Yun, S., Faraj, S., \& Sims, H.P., Jr. (2005). Contingent leadership and effectiveness of trauma resuscitation teams. Journal of Applied Psychology, 90(6), 1288-1296. https://doi.org/10.1037/0021-9010.90.6.1288

Zhang, X., \& Bartol, K.M. (2010). Linking empowering leadership and employee creativity: The influence of psychological empowerment, intrinsic motivation, and creative process engagement. Academy of Management Journal, 53(1), 107-128. https://doi.org/10.5465/AMJ.2010.48037118

Zhang, X., \& Zhou, J. (2014). Empowering leadership, uncertainty avoidance, trust, and employee creativity: Interaction effects and a mediating mechanism. Organizational Behavior and Human Decision Processes, 124(2), 150-164. https:// doi.org/10.1016/j.obhdp.2014.02.002

Zhang, Y. (2012). Expatriate development for cross-cultural adjustment: Effects of cultural distance and cultural intelligence. Human Resource Development Review, 12(2), 177-199. https://doi.org/10.1177/1534484312461637 